
\title{
ZS Research Square \\ Split household and smoking behavior of rural migrants in China
}

\section{Zicheng Wang}

Jinan university

\section{Qiushi Wu}

Jinan university

Juan Ming ( $\nabla$ mingjuan520888@126.com )

Guangdong University of Technology https://orcid.org/0000-0002-2677-3402

\section{Research article}

Keywords: smoking behavior, smoking abuse, split household, rural migrants, Hukou contraints, China

Posted Date: August 14th, 2020

DOI: https://doi.org/10.21203/rs.2.22498/v2

License: (c) (1) This work is licensed under a Creative Commons Attribution 4.0 International License. Read Full License 


\section{Abstract}

Background: With Hukou constraints, a large proportion of rural migrants have to leave part of their family members stay at hometown, the split household may induce smoking behavior among rural migrants in destination cites.

Objective: This study aims to address association between split household and smoking behavior, while the main discussion is to explore the differences between the three forms of split households-involving sole migration, couple migration, and family migration.

Method: A unique and comprehensive database named Rural Urban Migration in China (RUMiC-2009) is applied to explore the association between split household and the smoking behavior; Analyses are conducted using the Chi-square tests and Logit regression.

Results: The prevalence of smoking among family migrants (23.54\%) is less than those sole migrants $(25.46 \%)$ and couple migrants (35.13\%). The family migrants (OR=0.7445; $95 \% \mathrm{Cl}=0.5955,0.930)$ and couple migrants $(\mathrm{OR}=0.8785 ; 95 \% \mathrm{Cl}=0.6939,1.1121)$ are less prone to smoke than the sole migrants counterparts. The family migrants (Coefficient $=-0.0787 ; \mathrm{Cl}=-0.1229,-0.0346$ ) and couple migrants (Coefficient $=-0.0726 ; \mathrm{Cl}=-0.1188,-0.0264$ ) show lower lever of depression compared with the sole migration groups.

Conclusions: Split household is positively associated with the smoking behavior of rural migrants. While the depression may play as the potential transmission channel linked the spit household and smoking prevalence.

\section{Background}

China is a high-burden tobacco-use country, where nearly one-third $(28.1 \%)$ of the population smokes, including $52.9 \%$ of men and $2.4 \%$ of women[1], which has been linked to the chronic and often fatal diseases of the respiratory tract[2]. With rapid urbanization, about 288 million migrants move from rural to urban in 2018 [3], and they have become an indispensable force for China's industrialization and modernization [4]. However, a large part of them are highly susceptible to smoking [5-7]. A rich array of studies has explored the determinants of rural migrants' smoking prevalence [8]. Most previous researches have consistently concluded that life and work stress are main determinants for the smoking prevalence of rural migrants[9,10], where the life and work stress include but not are limited to low-quality employment, poor living conditions, unequal public service ,maladaptation to urban life and so on $[9,10,12-14]$. The rural migrants with high stress are more prone to trigger and aggravate smoking to obtain temporarily release [7]. Beyond that, there is also a consistent conclusion that the rural migrants' smoking prevalence is associated with age, gender, education attainments, income, occupation and migration durations[6-7,15]. 
However, the existing studies neglect a fact that Hukou system remains a fundamental institutional constraint in the process of migration integration in China. Without local urban Hukou, rural migrants can move to a new place but are not easy to share the same public services and welfare as local urban citizens $[14,18]$. Thus, the rural-urban migration is not a one way street, and most of rural migrants are temporary or circular [16-17].Most of them have to split their households between their rural origins and urban work locations, as some of the family members live in rural areas, whereas others have moved to cities looking for a job[19-22]. The household split including sole migration and couple migration has become an important social issue in China's urbanization process [29].

Split household a usually is co-occurred with rural migrants mental health status, such as the work stress, psychological distress, depressive symptoms [23; 30]. Moreover, previous studies also reported a positive association between depression /anxiety and smoking behavior [31][32]. Smoking was generally used as a common way of alleviating stress, and thus the split household may cause smoking behavior.

Nevertheless, previous studies pay little attention to the association between spit household and smoking behavior. Chen et al. (2004) found a negative correlation between living with relatives and the smoking prevalence [7], but their conclusion was drawn only through Pearson chi-square tests, without regression applied to conduct more robust results.

The present study aims to fill those gaps by using a unique survey named RUMiC to extend the discussion of association between spilt household and smoking behavior among rural migrants in China. Three issues are addressed as follows:

(1) Does the split household induce to smoking behavior?

(2) Are there any differential effect among three split-household forms?

(3) What is the potential mechanism linking the split household and smoking behavior?

This research contributes to the literature in three distinct ways. First, the present study emphasizes the association between split-household and the rural migrants' smoking behavior in China context, and it presents new evidence to understand the nexus between the smoking abuse and solitude due to household split. Second, a unique and comprehensive database named RUMiC is used to explore the relationship between split household and smoking prevalence. Third, the potential transmission channels linking the split household and smoking behavior are discussed by estimating the association between split household and depression.

\section{Method}

\section{Data and sample}

This study used data from Rural Urban Migration in China (RUMiC), which is initiated by a group of researchers at the Australian National University, the University of Queensland and the Beijing Normal University and supported by IZA Institute of Labor Economics. RUMiC consists of three independent 
surveys: the Urban Household Survey (UHS), the Rural Household Survey (RHS) and the Migrant Household Survey (MHS). The data we applied in the present study is derived from MHS, which collects rich information on household roster and personal characteristics, education and training backgrounds, employment situation, household income and expenditure during migration period. RUMiC covers 15 cities within nine-largest provinces sending and receiving migrants in China, namely, Bengbu, Chengdu, Chongqing, Dongguan, Guangzhou, Hefei, Hangzhou,Luoyang, Nanjing, Ningbo, Shanghai, Shenzen, Wuhan, Wuxi, and Zhengzhou (See Figure1).

About 5000 migrant households were collected in each wave, and the sampling frame of MHS was conducted by RUMiC team to overcome the problem of under-coverage [24].RUMiC established a list of 550,000 migrant workers, from which 5,000 samples were randomly selected. The sampling frame was established on workplaces (rather than residences), all businesses-including street vendors-in randomly selected enumeration areas within defined city boundaries were included. For each city, a sample of migrant workers was randomly selected within each workplace, based on their birth month. The enumerators subsequently conducted face-to-face interviews with migrant workers and their families [25].

RUMiC was launched in 2008, and three waves RUMiC-2008, RUMiC-2009 are available to apply from the IZA Institute of Labor Economics. But only the wave of 2009 collects smoking-related information.

RUMiC-2009 only provide the information of the household members who was living with the respondent, sharing incomes and expenditures at the time of interview, the data on the family members left behind especially the grandparents was not collected. Thus, present study is limited to the nuclear family only with married-couple and their young unmarried children, which is only defined as a single family nucleus with married-couple and their young children(age $\leq 16$ ). We also drop the incomplete nuclear family samples such as single parent family to ensure the specific split scenario portrayed as split between spouses as well as split between spouse and their children [22]. After deleting the missing samples and outliers, this study obtains 3738 valid migrant samples, which includes about 1995 males and 1743 females in 15 cities (the sample coverage as shown in Table 1)

\section{Ethnics Statement}

This study is a secondary analysis based on the data from the from the RUMiC conducted by a group of researchers at the Australian National University, the University of Queensland and the Beijing Normal University and was supported by the Institute for the Study of Labor (IZA)『all of which were subject to multiple stages of reviews by experts to address methodological, ethical and legal issues related to data collection. Final approvals of all RUMIC surveys were required from the Research Ethics Committee of National Bureau of Statistics of China to ensure that the data collection complied with ethical requirement according to the Statistics Act.

\section{Measures}


In the RUMiC, rural migrants are defined as rural laborers who move from rural areas to urban destinations within China. Internal migrants currently work in the surveyed cities but lack a local urban Hukou. The focal variable used in present study is split household, which are defined as the migrants' household arrangements between origin village and urban destination, includes three forms: sole migration, couple migration and family migration. Following Fan (2001) [22], we define the sole migration as the rural migrants who migrate solely, while both their spouse and children are left behind their hometown. Couple migration refers to migrants who migrate and reside together with their spouse but have no children resided together. Family migration is the household with the couple and all the children reside together at the same destination.

The variable of average cigarettes consumed per day is directly collected form the questionnaire item "How many cigarettes on average do you smoke per day now?". Daily smoking amount is measured by pack of cigarettes consumed per day, which was calculated by the average cigarettes consumed per day / 20. The smoking prevalence is defined as a dummy variable, which is set equal to 1 if migrants smoke at least 1 cigarette per day and 0 otherwise.

According to previous studies, controlled variables incorporate age (ref= age $<25)$, gender ( $r e f=f e m a l e)$, educational attainment (ref= junior middle school or less), monthly income (ref= income<1500), duration (ref=duration<5),industry (ref= others), job status (ref= others), work overtime $(r e f=n o)$, life satisfaction (ref= dissatisfied $)$.

\section{Modeling strategy}

All the analyses are conducted using the Stata 15.0. The Pearson chi-square tests are applied to examine the association between split household, controls and smoking prevalence.

Logit regression analyses are performed to explore the relationship between split household and smoking prevalence, while the demographic variables, employment traits as well as the life satisfaction and city dummies are incorporated as the controls. Tobit estimation on the Daily smoking amount was conducted to give a robust check. OLS regression is applied to discuss the potential transmitted channel linking split household and the smoking prevalence.

\section{Results}

\section{Baseline characteristics}

Table 1 presents the descriptive statistics, most of the rural migrants are young males, of the 3738 participants, 2624 are less than the 40 years old, and $53.37 \%$ of them are males. Most of them( $N=2915)$ have educational achievement at junior middle school or less, only $2.94 \%(\mathrm{~N}=110)$ of them completed education at the level of college or above. Over half $(\mathrm{N}=2104)$ of respondents are low-income employees, their monthly income (Yuan) were less than 2000. As for the migration duration, 55.67\% of them $(\mathrm{N}=2081)$ have stayed in the local city for more than five years. Nearly half of the participants $(\mathrm{N}=1852)$ 
work in the retail and hotel industry, whereas $18.96 \%(\mathrm{~N}=593)$ and $8.72 \%(\mathrm{~N}=326)$ of them engage in manufacture and construction. $38.09 \%(\mathrm{~N}=1424)$ of them are self-employed, and $32.32 \%$ of them experienced overtime .Of the 3738 participants , 255 are dissatisfied with the present life, while 1904 are satisfied with the current life.

Table 1 Baseline characteristics

\begin{tabular}{|c|c|c|c|c|c|}
\hline & Full sample & Smokers & Prevalence (\%) & $\mathrm{X} 2$ & $\mathrm{p}$ \\
\hline Household arrangement & & & & 45.29 & 0.000 \\
\hline Family migration & 1678 & 395 & 23.54 & & \\
\hline Couple migration & 1041 & 265 & 25.46 & & \\
\hline Sole migration & 1019 & 358 & 35.13 & & \\
\hline Age(years) & & & & 11.09 & 0.026 \\
\hline age $<25$ & 126 & 21 & 16.67 & & \\
\hline $25 \leq$ age $<30$ & 621 & 164 & 26.41 & & \\
\hline $30 \leq$ age $<35$ & 867 & 224 & 25.84 & & \\
\hline $35 \leq$ age $<40$ & 1010 & 281 & 27.82 & & \\
\hline $40 \leq$ age & 1114 & 328 & 29.44 & & \\
\hline Gender & & & & $1.1 e+03$ & 0.000 \\
\hline Female & 1743 & 28 & 1.61 & & \\
\hline Male & 1995 & 990 & 49.62 & & \\
\hline Educational attainment & & & & 5.418 & 0.067 \\
\hline Junior middle school or less & 2915 & 774 & 26.55 & & \\
\hline Senior middle school & 713 & 218 & 30.58 & & \\
\hline College or more & 110 & 26 & 23.64 & & \\
\hline Monthly income(Yuan) & & & & 27.88 & 0.00 \\
\hline income $<1500$ & 1307 & 292 & 22.34 & & \\
\hline $1500 \leq$ income $<2000$ & 797 & 248 & 31.12 & & \\
\hline $2000 \leq$ income $<3000$ & 1110 & 311 & 28.02 & & \\
\hline $3000 \leq$ Income & 524 & 167 & 31.87 & & \\
\hline Duration (years) & & & & 5.12 & 0.077 \\
\hline duration $<5$ & 1657 & 431 & 26.01 & & \\
\hline $5 \leq$ duration $<10$ & 1109 & 330 & 29.76 & & \\
\hline $10 \leq$ duration & 972 & 257 & 26.44 & & \\
\hline Industry & & & & 101.2 & 0.000 \\
\hline Construction & 326 & 165 & 50.61 & & \\
\hline Manufacture & 593 & 152 & 25.63 & & \\
\hline Retail & 1299 & 321 & 24.71 & & \\
\hline Hotel & 553 & 125 & 22.60 & & \\
\hline Others & 967 & 255 & 26.37 & & \\
\hline Job status & & & & 0.7983 & 0.372 \\
\hline Others & 2314 & 342 & 14.78 & & \\
\hline Self-employed & 1424 & 376 & 26.40 & & \\
\hline Over-time & & & & 8.92 & 0.000 \\
\hline No & 2530 & 651 & 25.73 & & \\
\hline Yes & 1208 & 367 & 30.38 & & \\
\hline Life satisfaction & & & & 5.47 & 0.065 \\
\hline Dissatisfied & 255 & 81 & 31.76 & & \\
\hline Neutral & 1579 & 446 & 28.25 & & \\
\hline satisfied & 1904 & 491 & 25.79 & & \\
\hline
\end{tabular}

\footnotetext{
${ }^{\mathrm{b}}$ P-value were calculated using Pearson chi-square tests
}

*significant $(\mathrm{p} \leq 0.05)$ 


\section{Univariate analysis}

As show in Table 2, 27.23\% of the migrants are smoker. The Chi-square tests indicate that the prevalence of smoking among sole migrants (35.13\%) are higher than those couple migrants $(25.46 \%)$ and family migrants (23.54\%).Males are more likely to smoke than females (49.62\% vs $1.61 \%)$. The migrants serve at the construction industry have higher likelihood to smoke than other sectors $(50.61 \%)$. The respondents involving in overtime job are more likely to smoking (30.38\% vs $25.73 \%)$ and the dissatisfied migrants have higher likelihood to smoking than counterparts (31.76\% vs $28.25 \%$ vs $25.79 \%$ )

Table 2 Sample Coverage

\begin{tabular}{l|r|r}
\hline \multicolumn{1}{c|}{ City } & \multicolumn{1}{c|}{$\mathbf{N}$} & \multicolumn{1}{c}{$\%$} \\
\hline Guangzhou & 273 & 7.3 \\
\hline Dongguan & 178 & 4.76 \\
\hline Shenzhen & 117 & 3.13 \\
\hline Zhengzhou & 302 & 8.08 \\
\hline Luoyang & 155 & 4.15 \\
\hline Hefei & 272 & 7.28 \\
\hline Bengbu & 209 & 5.59 \\
\hline Chongqing & 392 & 10.49 \\
\hline Shanghai & 439 & 11.74 \\
\hline Nanjing & 218 & 5.83 \\
\hline Wuxi & 126 & 3.37 \\
\hline Hangzhou & 339 & 9.07 \\
\hline Ningbo & 157 & 4.2 \\
\hline Wuhan & 279 & 7.46 \\
\hline Chengdu & 282 & 7.54 \\
\hline Total & 3,738 & 100 \\
\hline
\end{tabular}

\section{Multivariate analysis}

Multivariate analysis with Logit regression model is applied to identify independent variables associated with smoking prevalence, from which odd ratios (OR) and 95\% confidence intervals (Cl) are calculated.

Table 3 Multiple regression analysis 


\begin{tabular}{|c|c|c|c|c|c|c|}
\hline & \multicolumn{3}{|c|}{$\begin{array}{l}\text { Model 1(Prevalence of smoking) } \\
\text { Logit }\end{array}$} & \multicolumn{3}{|c|}{$\begin{array}{c}\text { Model 2(Daily smoking amount) } \\
\text { Tobit }\end{array}$} \\
\hline & OR & $95 \%, \mathrm{CI}$ & P-value & Partial Effects & $(95 \%, \mathrm{CI})$ & $\mathrm{P}$-value \\
\hline \multicolumn{7}{|l|}{ Household arrangement } \\
\hline Sole migration & Reference & & & & & \\
\hline Couple migration & 0.8785 & $0.6939,1.1121$ & 0.2820 & -0.0141 & $-0.0426,0.0144$ & 0.331 \\
\hline Family migration & 0.7445 & $0.5955,0.9306$ & 0.0100 & -0.0334 & $-0.0605,-0.0063$ & 0.016 \\
\hline \multicolumn{7}{|l|}{ Age(years) } \\
\hline age $<25$ & Reference & & & & & \\
\hline $25 \leq$ age $<30$ & 1.1377 & $0.6029,2.1468$ & 0.6910 & 0.0294 & $-0.0486,0.1074$ & 0.46 \\
\hline $30 \leq$ age $<35$ & 0.8942 & $0.4794,1.6678$ & 0.7250 & 0.0044 & $-0.0725,0.0812$ & 0.912 \\
\hline $35 \leq$ age $<40$ & 1.0111 & $0.5435,1.8810$ & 0.9720 & 0.0348 & $-0.0416,0.1111$ & 0.372 \\
\hline $40 \leq$ age & 1.1137 & $0.5996,2.0684$ & 0.7330 & 0.0447 & $-0.0313,0.1208$ & 0.249 \\
\hline \multicolumn{7}{|l|}{ Gender } \\
\hline Female & Reference & & & & & \\
\hline Male & 63.7841 & $43.1029,94.3882$ & 0.0000 & 0.4997 & $0.4580,0.5413$ & 0 \\
\hline \multicolumn{7}{|l|}{ Educational attainment } \\
\hline Junior middle school or less & Reference & & & & & \\
\hline Senior middle school & 1.0470 & $0.8355,1.3120$ & 0.6900 & 0.0019 & $-0.0256,0.0294$ & 0.893 \\
\hline College or more & 0.7000 & $0.4246,1.1539$ & 0.1620 & -0.0607 & $-0.1244,0.0031$ & 0.062 \\
\hline \multicolumn{7}{|l|}{ Monthly income(Yuan) } \\
\hline income $<1500$ & Reference & & & & & \\
\hline $1500 \leq$ income $<2000$ & 0.9853 & $0.7661,1.2672$ & 0.9080 & -0.0076 & $-0.0381,0.0228$ & 0.623 \\
\hline $2000 \leq$ income $<3000$ & 1.0066 & $0.7892,1.2839$ & 0.9580 & -0.0050 & $-0.0343,0.0242$ & 0.737 \\
\hline $3000 \leq$ Income & 0.9515 & $0.7079,1.2790$ & 0.7420 & -0.0005 & $-0.0366,0.0355$ & 0.977 \\
\hline \multicolumn{7}{|l|}{ Duration (years) } \\
\hline duration $<5$ & Reference & & & & & \\
\hline $5 \leq$ duration $<10$ & 1.1814 & $0.9570,1.4585$ & 0.1210 & 0.0166 & $-0.0089,0.0422$ & 0.203 \\
\hline $10 \leq$ duration & 1.0835 & $0.8570,1.3700$ & 0.5030 & 0.0026 & $-0.0259,0.0312$ & 0.856 \\
\hline \multicolumn{7}{|l|}{ Industry } \\
\hline Others & Reference & & & & & \\
\hline Construction & 1.4297 & $1.0397,1.9660$ & 0.0280 & 0.0712 & $0.0332,0.1092$ & 0 \\
\hline Manufacture & 0.6983 & $0.5209,0.9360$ & 0.0160 & -0.0238 & $-0.0603,0.0128$ & 0.202 \\
\hline Retail & 1.0736 & $0.8246,1.3978$ & 0.5980 & 0.0260 & $-0.0061,0.0581$ & 0.113 \\
\hline Hotel & 0.9999 & $0.7351,1.3601$ & 1.0000 & 0.0089 & $-0.0287,0.0464$ & 0.644 \\
\hline \multicolumn{7}{|l|}{ Job status } \\
\hline Others & Reference & & & & & \\
\hline Self-employed & 1.0220 & $0.7993,1.3068$ & 0.8620 & 0.0010 & $-0.0288,0.0309$ & 0.946 \\
\hline \multicolumn{7}{|l|}{ Work overtime } \\
\hline No & Reference & & & & & \\
\hline Yes & 1.2524 & $1.0225,1.5338$ & 0.0300 & 0.0172 & $-0.0073,0.0418$ & 0.169 \\
\hline \multicolumn{7}{|l|}{ Life satisfaction } \\
\hline Dissatisfied & Reference & & & & & \\
\hline Neutral & 0.8426 & $0.5876,1.2082$ & 0.3520 & -0.0388 & $-0.0811,0.0035$ & 0.072 \\
\hline satisfied & 0.7170 & $0.5012,1.0258$ & 0.0690 & -0.0581 & $-0.1002,-0.0160$ & 0.007 \\
\hline Constant & 0.0137 & $0.0058,0.0319$ & 0.000 & -- & --- & -- \\
\hline City Dummies & & Control & & & Control & \\
\hline
\end{tabular}


As shown in Table 3, the Logit estimations reveal that migrants of female (OR=63.7841; $95 \% \mathrm{Cl}=$ 43.1029,94.3882) smoke less than counterparts reference group. Rural migrants engaged in the construction sector $(\mathrm{OR}=1.4297 ; 95 \% \mathrm{Cl}=1.0397,1.9660)$ and overtime jobs $(\mathrm{OR}=1.2524 ; 95 \% \mathrm{Cl}=$ $1.0225,1.5338)$ are likely to smoke more.

As for the influence of split household, the results show that the family migrants $(\mathrm{OR}=0.7445 ; 95 \% \mathrm{Cl}=$ $0.5955,0.9306)$ and couple migrants $(\mathrm{OR}=0.8785 ; 95 \% \mathrm{Cl}=0.6939,1.1121)$ are less susceptible to smoke than the sole migrants counterparts, but the coefficient of couple migrants is not significant.

This research also applies Tobit regression to verify the relationship between split household and rural migrants' daily smoking amount, the results are shown in Table 2 model 2 . The partial effects of Tobit estimations are robust with the Logit regression (As shown in Table 4). The results demonstrate that the family migrants smoke less than the sole migrant counterparts(Partial Effects $=-0.0334 ; \mathrm{Cl}=$ $-0.0605,-0.0063)$ ). while the that couple migrants are also likely to smoke less than the sole migrants( Partial Effects $=-0.0141 ; \mathrm{Cl}=-0.0426,0.0144)$,but the effect is not significant at $95 \%$ confidence level.

\section{Mechanism analysis}

What is the potential mechanism linking the split household and smoking behavior? The present study claims that mental health such as depression may serve as the potential mechanism linking split household and smoking behavior. That is, split household may be positively related with depression, which will cause smoking behavior. To investigate the transmission channel, we further explore the relationship between split household and depression.

As shown in Table 4, Couple migration (Coefficient $=-0.0726 ; \mathrm{Cl}=-0.1188,-0.0264$ ) and family migration (Coefficient $=-0.0787 ; \mathrm{Cl}=-0.1229,-0.0346$ ) produce lower level of depression than the sole migrants.

Table 4 Transmission channel 


\begin{tabular}{|c|c|c|c|}
\hline & \multicolumn{3}{|c|}{ Model 3} \\
\hline & Coefficient & $95 \%$, CI & P-value \\
\hline \multicolumn{4}{|l|}{ Household arrangement } \\
\hline \multicolumn{4}{|l|}{ Sole migration } \\
\hline Couple migration & -0.0726 & $-0.1188,-0.0264$ & 0.002 \\
\hline Family migration & -0.0787 & $-0.1229,-0.0346$ & 0 \\
\hline \multicolumn{4}{|l|}{ Age(years) } \\
\hline \multicolumn{4}{|l|}{ age $<25$} \\
\hline $25 \leq$ age $<30$ & -0.0226 & $-0.1206,0.0753$ & 0.651 \\
\hline $30 \leq$ age $<35$ & -0.0330 & $-0.1283,0.0623$ & 0.498 \\
\hline $35 \leq$ age $<40$ & -0.0743 & $-0.1698,0.0213$ & 0.127 \\
\hline $40 \leq$ age & -0.0450 & -0.1398 & 0.352 \\
\hline \multicolumn{4}{|l|}{ Gender } \\
\hline \multicolumn{4}{|l|}{ Female } \\
\hline Male & 0.0674 & $0.0325,0.1022$ & 0 \\
\hline \multicolumn{4}{|l|}{ Educational attainment } \\
\hline \multicolumn{4}{|c|}{ Junior middle school or less } \\
\hline Senior middle school & 0.0260 & -0.0182 & 0.249 \\
\hline College or more & 0.0664 & $-0.0238,0.1566$ & 0.149 \\
\hline \multicolumn{4}{|l|}{ Monthly income(Yuan) } \\
\hline \multicolumn{4}{|l|}{ income $<1500$} \\
\hline $1500 \leq$ income $<2000$ & 0.0300 & -0.0174 & 0.215 \\
\hline $2000 \leq$ inc ome $<3000$ & 0.0002 & -0.0448 & 0.993 \\
\hline $3000 \leq$ Income & -0.0024 & -0.0617 & 0.937 \\
\hline \multicolumn{4}{|l|}{ Duration (years) } \\
\hline \multicolumn{4}{|l|}{ duration $<5$} \\
\hline $5 \leq$ duration $<10$ & -0.0130 & -0.0536 & 0.529 \\
\hline $10 \leq$ duration & -0.0237 & -0.0689 & 0.303 \\
\hline \multicolumn{4}{|l|}{ Industry } \\
\hline \multicolumn{4}{|l|}{ Others } \\
\hline Construction & 0.0311 & $-0.0384,0.1006$ & 0.38 \\
\hline Manufacture & -0.0274 & $-0.0841,0.0293$ & 0.344 \\
\hline Retail & -0.0272 & $\begin{array}{ll}-0.0776, & 0.0231\end{array}$ & 0.289 \\
\hline Hotel & -0.0014 & $-0.0598,0.0571$ & 0.964 \\
\hline \multicolumn{4}{|l|}{ Job status } \\
\hline \multicolumn{4}{|l|}{ Others } \\
\hline Self-employed & 0.0891 & $0.0411,0.1372$ & 0 \\
\hline Work overtime & & & \\
\hline No & & & \\
\hline Yes & 0.0120 & $-0.0270,0.0510$ & 0.547 \\
\hline Life satisfaction & & & \\
\hline Dissatisfied & & & \\
\hline Neutral & 0.1217 & $0.0449,0.1986$ & 0.002 \\
\hline satisfied & 0.2191 & $0.1431,0.2950$ & 0 \\
\hline Constant & 3.136 & $3.000,3.272$ & 0 \\
\hline City Dummies & & Control & \\
\hline
\end{tabular}


The estimations from Logit confirm that family migrants have fewer probabilities to smoke than sole migrants, which imply that family migration is beneficial for smoking control. Family migrants showed a $25.55 \%$ less likelihood to be current smokers relative to sole migrants counterparts, while the partial effects in the Tobit estimation shows that the predicted value of smoking amounts is 0.0334 packets less for family migrants than for sole migrants. The potential reason may be that sole migration is significantly associated with loneliness[26], that is , migration with the whole family members together, especially migrated with their children together would boost their well-being[27].Those would release the work and life stress, which may induce to a decrease of smoking behavior. Another possible reason is that with migrated children in the family, the male smokers would reduce the smoking behavior to maintain a good living environment for their children. The results also confirm that couple migrants are less to smoke, but it is not significant. This may be because the incomplete family migration can partly weaker the smoking behavior, while leaving children stay behind has depressing impact[28], which would induce to smoking behavior to relieve loneliness for couples migrants.

In addition, the estimations also reveal that males are more likely to smoke than females, which is consistent with the previous studies confirming that rural male migrants are more likely to be smoker than females $[7,15]$. The migrants engaged in construction sector have more likelihood to smoke than the other sectors. It is consistent with the general conclusion that smoking behavior is more prevalence among the construction rural workers due to its high stress job [8].The migrants engaging in over-time job are at a higher level of risk for cigarette smoking, which implies that over-time work may induce a high level of psychosocial stress and high rates of mental problems for migrant workers, which in turn increase the susceptibility to cigarette smoking.

\section{Conclusion}

\section{Main findings}

This study discusses the association between split household and smoking behavior in China context by using a unique and comprehensive database named RUMiC. The results from Pearson chi-square tests show that males have more probability to smoke than females. The estimations from Logit confirm that family migrants and couple migrants are less likely to smoke than sole migrants, but the latter is not significant. The potential reason may be that family migration and couple migration can alleviate the depression and improve the well-being of migrants which in turn decrease the susceptibility to smoking. .

\section{Study limitations}

Our research has some limitations. Firstly, the present papers mainly focus on exploring the correlations, thus the causality discussion is limited. Secondly, without related information, the regression has no chance to capture the effect of disease, parents and other relative left behind, local social network which are also important determinants for smoking behavior, while the expenditure of smoking is un-discussed. Thirdly, based on single question "How many cigarettes on average do you smoke per day now?", the 
derived inference smoking amount may be biased, so we mainly explored the smoking prevalence instead of smoking amounts.

\section{Implications}

This study also sheds insight into current smoking control policy in urban China. Family migration is a valid way to weaken smoking behavior, thus it should be highly highlighted to attach importance to harmony and combination of all kinds of migration policy tools to encourage family migration.

\section{Abbreviations}

Rural Urban Migration in China (RUMiC); Odds ratios (OR); Confidence interval (Cl)

\section{Declarations}

\section{Ethics approval and consent to participate}

Not applicable

\section{Consent for Publication}

Not applicable.

\section{Availability of data and material}

The $\mathrm{RUMiC}$ is available from the IZA upon reasonable research request. RUMiC can be requested from the website of IZA: https://datasets.iza.org/dataset/58/longitudinal-survey-on-rural-urban-migration-in-china

\section{Competing interests}

The authors declare that they have no competing interests.

\section{Funding}

This article is funded by the National Social Science Fund of China (Granted number 17BJY044\&18ZDA081)

\section{Authors' contributions}

Zicheng Wang took leadership and responsibility for the research activity planning and made substantial contributions to the conception and design of the Programme. Jiachun Liu worked on the statistical analysis of the data. Juan Ming drafted the concept of the paper as well as participated in finalizing the manuscript. All authors read and approved the final manuscript.

\section{Acknowledgements}


Not applicable.

\section{References}

1. Chinese Center for Disease Control and Prevention: Global Adult Tobacco Survey (GATS). (2011).China 2010 Country Report. Beijing: China Sanxia Press.94-95

2. Gu D, Kelly TN, Wu X, Chen J, Samet JM., Huang JF,et al. (2009). Mortality attributable to smoking in China. New England Journal of Medicine. 360(2),150-159.

3. China Labour Bulletin. Migrant Workers and Their Children. 2019. Available from: https://clb.org.hk/content/migrant-workers and-their-children.

4. Chan KW (2012). Migration and development in China: Trends, geography and current issues. Migration and Development. 1(2), 187-205.

5. Wu J, Yang T, Rockett IR, Xing R, Karalic S, Li Y, Zhang Y. (2001).Nicotine dependence among ruralurban migrants in China. BMC public health. 11(1), 296.

6. Wan X, Shin SS, Wang Q, Fisher RH, Liu H, Ding D, Yang G, Novotny TE.(2011). Smoking among young rural to urban migrant women in China: a cross-sectional survey. PLoS One. 6(8).e23028.

7. Chen X, Li X, Stanton B, Fang X, Lin D, Cole M , et al. (2004).Cigarette smoking among rural-to-urban migrants in Beijing, China. Preventive Medicine. 39(4), 666-673.

8. Liu Y, Gao J, Shou J, Xia H, Shen Y, Zhu S, Pan Z. (2016). The prevalence of cigarette smoking among rural-to-urban migrants in China: a systematic review and meta-analysis. Substance use \& misuse. 51(2), 206-215.

9. Chen X, Stanton B, Li X, Fang X, Lin D.(2008). Substance use among rural-to-urban migrants in China: a moderation effect model analysis. Subst Use \& Misuse. 43(1),105-24.

10. Cui X, Rockett IR, Yang T, Cao R.(2012).Work stress, life stress, and smoking among rural-urban migrant workers in China. BMC Public Health. 12(1),979.

11. Yang T, Wu J, Rockett IR, Abdullah AS, Beard J, Ye J.(2009).Smoking patterns among Chinese ruralurban migrant workers. Public Health . 123(11),743-749.

12. Liu Z, Florkowski W J, Chen H. Gender Differences, Social Isolation and Rural Migrants' Cigarette Smoking. In: 2019 Annual Meeting, July 21-23, Atlanta, Georgia (No. 290964). Agricultural and Applied Economics Association.

13. Wong, DFK, Li CY, Song HX.(2007). Rural migrant workers in urban china: living a marginalised life. International Journal of Social Welfare.16(1),32-40.

14. Wang Z.(2011).Social security for China's migrant workers. International Labour Review. 150(12), $177-187$.

15. Liu Y, Song H, Wang T, Wang T, Yang H, Gong J, et al.(2015).Determinants of tobacco smoking among rural-to-urban migrant workers: a cross-sectional survey in Shanghai. BMC Public Health. 15(1),131. 
16. Shen J.(2002).A study of the temporary population in Chinese cities. Habitat International. 26(3),363377.

17. Du H, Li SM, Hao P. (2018).'Anyway, you are an outsider': Temporary migrants in urban China. Urban Studies. 55(14),3185-3201.

18. Wu F. (2004). Urban poverty and marginalization under market transition: the case of Chinese cities. International Journal of Urban and Regional Research. 28(2), 401-423.

19. Wang C, Zhang C, Ni J, Zhang H, Zhang J. (2019).Family migration in China: Do migrant children affect parental settlement intention?. Journal of Comparative Economics. 47(2), 416-428.

20. Wu W. (2002)Migrant housing in urban China: choices and constraints. Urban Affairs Review. 38(1),90-119.

21. Jingzhong Y, Lu P. (2011).Differentiated childhoods: impacts of rural labor migration on left-behind children in China. The Journal of peasant studies. 38(2),355-377.

22. Fan CC, Sun M, Zheng S.(2011).Migration and split households: a comparison of sole, couple, and family migrants in Beijing, China. Environment and Planning A. 43(9),2164-2185.

23. Hutchings K, McNulty Y. (2018). Split family expatriation: Perspectives from expatriates and their career spouses. In: McNulty Y (Ed.).Research Handbook of Global Families: Implications for International Business. Cheltenham, UK: Edward Elgar; 2018.p.1-28.

24. Akgüç M, Giulietti C, Zimmermann KF.(2014).The RUMiC longitudinal survey: Fostering research on labor markets in China. IZA Journal of Labor \& Development. 3(1), 5.

25. Tang, Z. (2012). The great migration: Rural-urban migration in China and Indonesia. Canadian Studies in Population, 39(3-4), 129-130.

26. Zhong B, Xu Y, Jin D, Zou X, Liu T.(2016).Prevalence and correlates of loneliness among Chinese service industry migrant workers: A cross-sectional survey. Medicine (Baltimore). 95(24):e5074. PMID: 27310992; PMCID: PMC4998478..

27. Démurger S, Li S, Xu H.(2014).Internal migration, family living arrangements and happiness in China. In : 6th Annual Joint Workshop on Socio-Economics, FERDI, Fudan University, Paris 1 University and SHUFE, 26-27, Paris, France.

28. Knight J, Gunatilaka R. (2010). Great expectations? The subjective well-being of rural-urban migrants in China. World development. 38(1),113-124.

29. Chen Y., Chen H., Liu, J. (2019).Household Split, Income, and Migrants' Life Satisfaction: Social Problems Caused by Rapid Urbanization in China. Sustainability.11, 3415.

30. Mucci N.,Traversini V., Giorgi G.,Tommasi E., De Sio S., Arcangeli G.(2020).Migrant Workers and Psychological Health: A Systematic Review. Sustainability.12, 120.

31. Breslau N, Peterson E L , Schultz L R, et al.(1998).Major Depression and Stages of Smoking: A Longitudinal Investigation[J]. Arch Gen Psychiatry, 55(2),161-166.

32. Meg, F. , Taylor, A. E. , Meryem, G. , \& Munafò Marcus R. (2017). The association of cigarette smoking with depression and anxiety: a systematic review. Nicotine \& Tobacco Research(1), 3-13. 


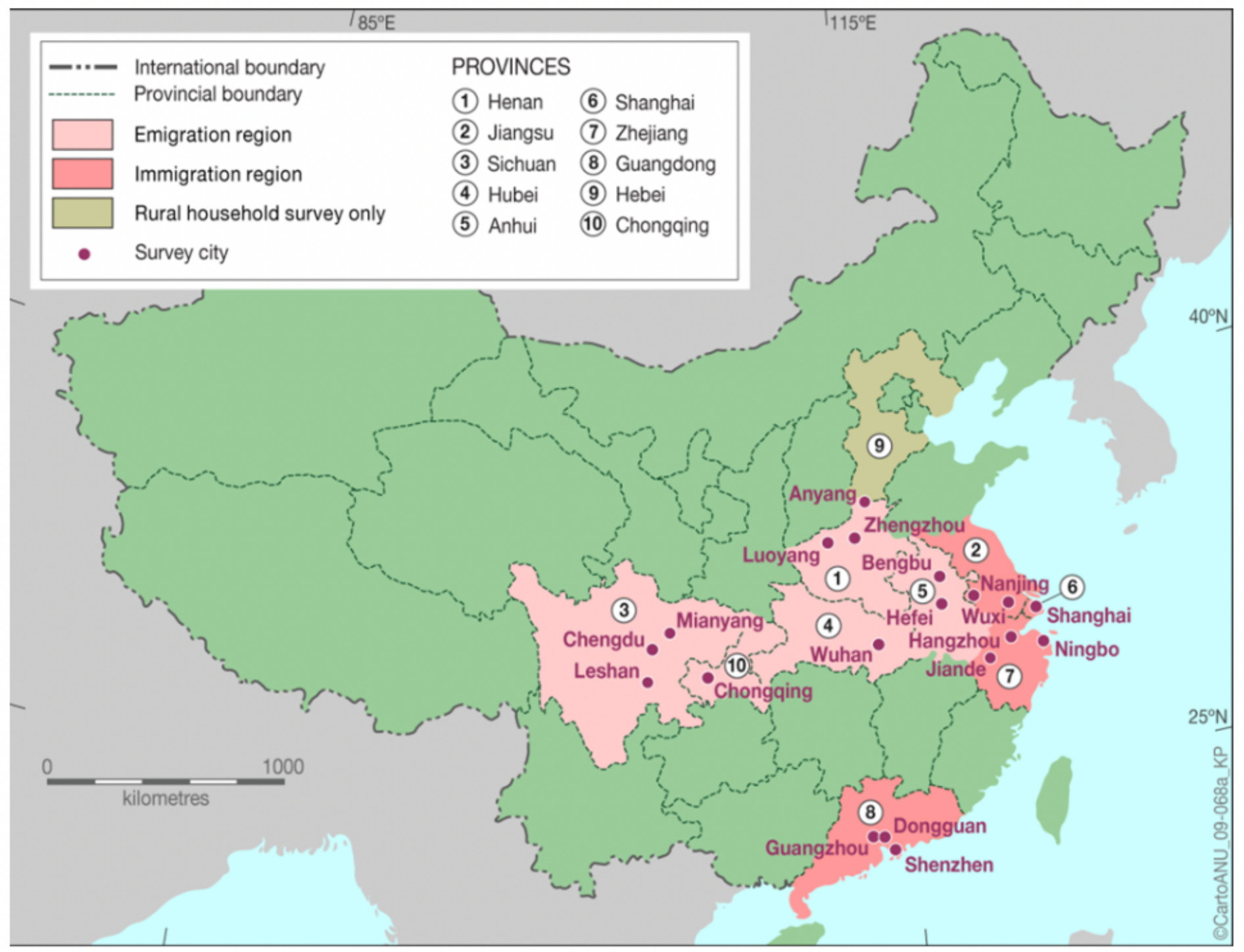

\section{Figure 1}

Sampling map. Note: The designations employed and the presentation of the material on this map do not imply the expression of any opinion whatsoever on the part of Research Square concerning the legal status of any country, territory, city or area or of its authorities, or concerning the delimitation of its frontiers or boundaries. This map has been provided by the authors. 